\title{
Modelling and Characterizing the Adhesion of Parallel-Grooved Interface between Concrete Lining Structure and Geopolymer by Wedge Splitting Method
}

\author{
Zhaopeng Yang, ${ }^{1}$ Ya Wei, ${ }^{2}$ and Linbing Wang $\mathbb{C}^{1,3}$ \\ ${ }^{1}$ National Center for Materials Service Safety, University of Science and Technology Beijing, Beijing 100083, China \\ ${ }^{2}$ Key Laboratory of Civil Engineering Safety and Durability of China Education Ministry, Department of Civil Engineering, \\ Tsinghua University, Beijing 100084, China \\ ${ }^{3}$ Department of Civil and Environmental Engineering, Virginia Tech, Blacksburg, VA 24061, USA \\ Correspondence should be addressed to Linbing Wang; wangl@vt.edu
}

Received 24 August 2020; Revised 21 October 2020; Accepted 29 October 2020; Published 17 November 2020

Academic Editor: Dongyu Niu

Copyright (c) 2020 Zhaopeng Yang et al. This is an open access article distributed under the Creative Commons Attribution License, which permits unrestricted use, distribution, and reproduction in any medium, provided the original work is properly cited.

\begin{abstract}
A new method for increasing the interface resistance between geopolymer coating and concrete lining structure without applying the organic binder was suggested in this study. Parallel grooves with different depths and orientations were milled on the top surface of concrete block, and well-blended geopolymer mixture (Na-PSS type geopolymer: Sodium poly-sialate-siloxo) was coated upon the grooved interface. The wedge splitting (WS) experiments were conducted to compare the interface adhesion capacity of specimens with different groove width/depth ratios and groove orientations. The average energy release rate (ERR) was calculated by integrating the $\mathrm{P}_{\mathrm{v}}$-CMOD diagram to quantify the interfacial fracture toughness. To understand the interface strength mechanisms and the fracture mode at the front crack mouth, franc 3D simulation was carried out to segregate the mixed fracture mode to determine the initial pure stress intensity factors $\left(K_{\mathrm{I}}, K_{\mathrm{II}}, K_{\mathrm{III}}\right)$ at the crack mouth. Both the experiments and simulation results indicated that the highest interface fracture toughness was reached by the double diagonal parallel grooves with 0.375 width/depth ratio. These findings put forward a promising attaching method for efficient and reliable passive fire protection coating, with the aim of decreasing the risk of layer delamination in highway tunnels.
\end{abstract}

\section{Introduction}

The concrete lining structures in underground tunnels are susceptible to fire hazards due to their large length/width ratio and narrow enclosure space. Damage to the concrete lining structure is the primary reason for rapidly decreasing the safety of a tunnel. A growing body of literature has recognized the importance of passive fire protection coating, which is a relatively efficient and economic method for eliminating this potential threat.

Geopolymer [1] is a man-made two-component stonelike material with excellent fire resistance. Any material that contains silica and alumina could be activated by alkali and polymerized into geopolymer, such as the meta-kaolin, furnace slag, and fly ash. Over the past two decades, numerous systematic investigations have focused on geopolymer's thermal conductivity and heat isolation along with the variation of the ingredients [2-4]. Singh et al. [5] assessed a mortar/concrete made with geopolymeric binder and tested its bond strength with aggregate; Cheng and Chiu [6] described a mixture of geopolymer and blast furnace slag and set a $10 \mathrm{~mm}$ thick geopolymer panel exposed to $1100^{\circ} \mathrm{C}$ fire. Rahman and Radford [7] tested the interfacial bond strength of the nanofiber geopolymer and evaluated the pure mode I fracture toughness with different factors. Zhang et al. [8] coated $5 \mathrm{~mm}$ thick geopolymer over the structure rectangular cross-section (RC) beam and compared it with the $\mathrm{RC}$ beam strengthened with fiber sheet.

Although most researchers claim that there are no clear delamination phenomena during the fire test for the 
geopolymer coating, this may be because their coating was relatively thin ( $5 \mathrm{~mm}$ thickness or lower) in their experiments. To prevent serious fire accidents, the requirement of the thermal barrier coating thickness of common material in the high way tunnels is estimated to be $20-30 \mathrm{~mm}$. Along with the increment of the coating thickness, the failure mode of layered structure may switch from thin film coating (plane stress) to unignorable thickness coating (plane strain), and the chances of delamination can substantially increase. Another problem in previous researcher's tests was that the geopolymer coating and the concrete base were considered as indivisible whole system, and the experiment data is insufficient to characterize the adhesion ability between the geopolymer coating and concrete base. Moreover, these approaches have failed to address the potential delamination threat due to the different coefficient of thermal strain between the concrete $\left(0.003\right.$ to 0.006 at $\left.300^{\circ} \mathrm{C}\right)$ and geopolymer coating $\left(-0.01\right.$ to -0.02 at $\left.250^{\circ} \mathrm{C}\right)[8,9]$.

Currently, to prevent the debonding threat of the thermal barrier coating in concrete lining structures, the organic binders need to be painted underneath the geopolymer coating. However, the bonding strength of epoxy resin or vinyl ester decreases dramatically when the temperature reaches a critical level. Recent evidence suggests that the bond strength of these organic binders remains only $40 \%$ of the original value when the temperature reaches around $140^{\circ} \mathrm{C}$. As these carbon-based materials have limited reliability in fire attack, the challenge for the geopolymer coating is to increase the interface adhesion ability without utilizing the organic binder to minimize the possibility of delamination.

This study focuses on the quantification of the interfacial adhesion between concrete and geopolymer coating by the wedge splitting (WS) experiments and thoroughly investigates the interfacial fracture resistance of the parallel groove interface with different width/depth ratios and groove orientations. Furthermore, the mixed fracture mode partition was analyzed by the Franc 3D method to compare the different fracture modes at the front crack mouth and to support the experiment results.

\section{Wedge Splitting Experiments}

2.1. The Substrate Shotcrete Base. The concrete lining structure in the highway tunnel is a multilayer system, and the outermost layer of the concrete lining structure is used to ensure the clear space of the tunnel and acts as a permanent support structure. We chose the concrete block sample with the same grading proportion of the outmost layer structure to quantify the interfacial adhesion ability. Guided by Chinese GB 50086-2015 (Technical Code for Ground Anchorages and Shotcrete Support), the China ISO Standard Sand was selected as the fine aggregate for this experiment. The particle size distribution of the sand is shown in Table 1.

Due to the characteristics of shotcrete construction, when selecting the mix proportion of shotcrete, it is necessary not only to meet the requirements of structure mechanical properties of shotcrete (compressive, tensile, and bonding strength), but also to keep the shrinkage
TABle 1: The particle size distribution of standard sand.

\begin{tabular}{lcc}
\hline No. & Mesh size $(\mathrm{mm})$ & Cumulative sieve residue (\%) \\
\hline 1 & 2.0 & 0.0 \\
2 & 1.6 & $7 \pm 5$ \\
3 & 1.0 & $33 \pm 5$ \\
4 & 0.5 & $67 \pm 5$ \\
5 & 0.2 & $87 \pm 5$ \\
6 & 0.1 & $99 \pm 1$ \\
\hline
\end{tabular}

deformation value of shotcrete minimum. In order to transport the shotcrete in the pipe on the construction set, the amount of aggregate is much less than that in the ordinary concrete, while the amount of sand increases, up to $50 \%$. With high sand ratio, the aggregate total surface area will increase, and more cement slurry will be required to wrap the aggregate surface to meet the requirements of shotcrete strength. The mix proportion of general shotcrete mixture in our experiment is as follows: the weight ratio of cement and sand is $1: 4 \sim 1: 4.5$, the sand ratio is $45 \% \sim 55 \%$, the water cement ratio is $0.04 \sim 0.45$, and the dosage of accelerator should be determined by experiment according to the product performance.

For the convenience to fit with the Hydraulic Mechanic Test System (HMTS), the concrete cubic size was chosen as $150 \mathrm{~mm}^{*} 150 \mathrm{~mm}^{*} 130 \mathrm{~mm}$, in which the $20 \mathrm{~mm}$ height was reserved for the geopolymer coating. All the ingredients are thoroughly mixed plus over 1.5 mins of vibration to ensure an even distribution. A total number of 20 blocks of concrete samples are prepared for the same batch to achieve the consistency for the following test.

2.2. The Aluminosilicate Raw Material. The geopolymer can be synthesized by mixing the meta-kaolin binder, 3\% sodium silicate $\left(\mathrm{Na}_{2} \mathrm{SiO}_{3}\right)$, and $3 \%$ alkaline hydroxide $(\mathrm{NaOH})$ together $[11,12]$. Meta-kaolin is an aluminosilicate rich kaolin clay mineral, which was calcined at $700^{\circ} \mathrm{C}$ for 10 hours and grounded into fine-grained powder (200 mesh). The diameter size for the meta-kaolin particle is less than $10 \mu \mathrm{m}$ to achieve the maximum reactivity. The composition of the meta-kaolin mineral was shown in Table 2.

The properties of geopolymer may be distinctive due to the molecular structure and the raw materials that have been used. Three types of geopolymer were categorized by varying the $\mathrm{Si} / \mathrm{Al}$ ratio, as shown in Table 3.

To reach the maximum heat isolation capacity, we chose the Na-PSS type geopolymer. The most important mole ratio for Na-PSS type geopolymer is $3.5 \leq\left(n\left(\mathrm{SiO}_{2}\right) / n\left(\mathrm{Al}_{2} \mathrm{O}_{3}\right)\right) \leq 4$ [12]. For every $100 \mathrm{~g}$ of meta-kaolin, $60 \mathrm{~g}$ of sodium silicate is required. For each concrete block, the geopolymer coating needs to reach a thickness of $20 \mathrm{~mm}$ to meet the fire protection requirements. As the high-reactivity cement, metakaolin can be easily dissolved into alkaline solution and breaks down into $\mathrm{SiO}_{2}$ and $\mathrm{AlO}_{4}$. The weight ratio of $\mathrm{SiO}_{2}$ and $\mathrm{Al}_{2} \mathrm{O}_{3}$ in the meta-kaolin powder was $55 \%$ and $44 \%$, respectively.

The sodium silicate $\left(\mathrm{Na}_{2} \mathrm{SiO}_{3}\right)$ is white powder and needs to disperse in hot water $\left(45^{\circ} \mathrm{C}-55^{\circ} \mathrm{C}\right)$ with sodium hydroxide. 
TABLe 2: Compositions of highly active meta-kaolin powder.

\begin{tabular}{lcccccccc}
\hline $\mathrm{SiO}_{2}$ & $\mathrm{Al}_{2} \mathrm{O}_{3}$ & $\mathrm{Fe}_{2} \mathrm{O}_{3}$ & $\mathrm{TiO}_{2}$ & $\mathrm{CaO}$ & $\mathrm{MgO}$ & $\mathrm{K}_{2} \mathrm{O}$ & $\mathrm{Na}_{2} \mathrm{O}$ & $\mathrm{LOI}$ \\
\hline 54.06 & 43.12 & 0.76 & 0.24 & 0.17 & 0.06 & 0.55 & 0.06 & 0.98 \\
Activity Index & $\mathbf{1 1 1 0}$ & & & & & & & \\
\hline
\end{tabular}

TABLE 3: The Composition of three types of geopolymer [11].

\begin{tabular}{lcccc}
\hline Types of geopolymer & Chemical formula & $n\left(\mathrm{SiO}_{2}\right) / n\left(\mathrm{Al}_{2} \mathrm{O}_{3}\right)$ & $n\left(\mathrm{NaO}^{2} / n\left(\mathrm{Al}_{2} \mathrm{O}_{3}\right)\right.$ & $n\left(\mathrm{H}_{2} \mathrm{O}\right) / n\left(\mathrm{Al}_{2} \mathrm{O}_{3}\right)$ \\
\hline PS & $\mathrm{Na}_{2} \mathrm{Si}_{2} \mathrm{Al}_{2} \mathrm{O}_{8}(6-7) \mathrm{H}_{2} \mathrm{O}$ & 2 & 1 & 6 \\
PSS & $\mathrm{Na}_{2} \mathrm{Si}_{2} \mathrm{Al}_{2} \mathrm{O}_{12}(2-3) \mathrm{H}_{2} \mathrm{O}$ & 4 & 1 & 3 \\
PSDS & $\mathrm{Na}_{2} \mathrm{Si}_{2} \mathrm{Al}_{2} \mathrm{O}_{16} \mathrm{H}_{2} \mathrm{O}$ & 6 & 1 & 2 \\
\hline
\end{tabular}

After stirring for $5 \mathrm{~min}$ with a magnetic stirrer, this warm mixture solution was then poured into the orange metakaolin powder. The final ingredient distribution was shown in Table 4.

After the raw materials were thoroughly mixed, the geopolymer paste was poured into the mould with the solid concrete block at the bottom, as shown in Figure 1. To reach the maximum adhesion ability, the contact surface of the concrete block was cleaned by sand paper to remove the dirt. The mould was kept in a humidity- and temperature-controlled chamber. The testing block was then covered with a moist towel to prevent from drying and microcracking on the surface.

It took 7 days before the geopolymer was fully hardened and the plastic moulds were removed. Two steel bars were positioned symmetrically $15 \mathrm{~mm}$ from the initial cracking interface and glued upon the top surface of each testing sample with epoxy resin, as shown in Figure 2. The steel bars were designed to be attached to the flange of the load transferring clamps.

2.3. Procedures of Wedge Splitting Test. The WS [13-17] test is a displacement-driven experiment to quantify the material adhesion ability and the fracture energy of the crack. To get precise results, one principle preassumption is that no energy was dissipated except in the fracture process zone and the average work done is all used for crack propagation. Selfweight of the specimen not affecting the final result is one of the advantages of the WS method compared to others such as the three-point bending, compact tension, and direct stretch methods. Another advantage is that the WS test reduces the impact of the vertical load and effectively increases the stiffness of the testing machine by introducing the clamp structure. In addition, a suitable wedge angle shall moderate the requirement of vertical load and easily transfer it to the horizontal load, which effectively increases the data accuracy of the whole testing system.

The specimen was subjected to a constant rate of displacement during the entire loading process. The loading frame in this experiment was an HMTS with a loading acquisition system. The wedge splitter was contacted to the hydraulic testing machine rigidly and provided the vertical displacement; the loading plates were placed symmetrically at both sides of the initial fracture interface (shown in
TABLE 4: Raw material weight list.

\begin{tabular}{lccc}
\hline Geopolymer (g) & $\begin{array}{c}\text { Sodium } \\
\text { silicate }(\mathrm{g})\end{array}$ & $\begin{array}{c}\text { Warm } \\
\text { water }(\mathrm{g})\end{array}$ & $\begin{array}{c}\text { Sodium } \\
\text { hydroxide }(\mathrm{g})\end{array}$ \\
\hline 800 & 500 & 270 & 40 \\
\hline
\end{tabular}

Figure 3). The components of the loading transfer clamps included two loading plates and one wedge splitter. Although, theoretically, the tangent wedge angle should be as small as possible, a tangent angle $\theta$ of $15^{\circ}$ was chosen in this study from a practical perspective. The horizontal force can be acquired by

$$
p_{h}=\frac{P_{v}}{2 \tan \theta}
$$

The crack mouth opening displacement (CMOD) was recorded simultaneously by a digital extensometer (a linear variable displacement transducer). The extensometer in this experiment was YYJ-5/15-L (manufactured by Ji'nan Li Dong Test Equipment Co., Ltd, China), which can measure the CMOD values with a precision up to $0.001 \mathrm{~mm}$. All specimens were tested under the same vertical displacement control rate at $0.00125 \mathrm{~mm} / \mathrm{s}$, which is equivalent to $0.0004 \mathrm{~mm} / \mathrm{s}$ in the horizontal direction. To ensure that fracture initiated along the interface, the loading point needed to be close to the crack mouth.

As the crack resistance capacity is positively proportional to the energy release rate (ERR), the EER method is ideal for quantifying the adhesion ability of the interface as long as the additional bending has less effect around the crack tip fracture zone and the measured CMOD is close to the real value. The initiation of a crack in the specimen will change the compliance of the test sample, while, in the WS test, such changes in compliance can be successfully avoided. Because of the high stiffness of these sections, the energy required for the geopolymer and concrete sections to undergo elastic change was much higher compared with the interfacial fracture initiation energy.

\subsection{Parallel-Grooved Surface with Different Width/Depth} Ratios and Groove Orientation. Grooving [19-21] is one conventional method to enhance the interfacial toughness and prevent the debonding phenomenon. In this study, the parallel grooves were milled vertically onto the concrete top 


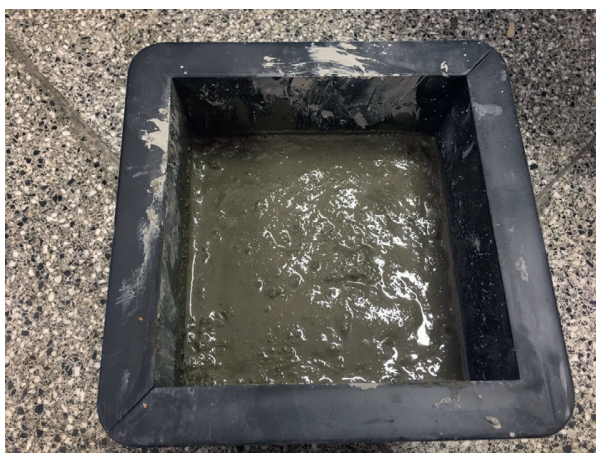

(a)

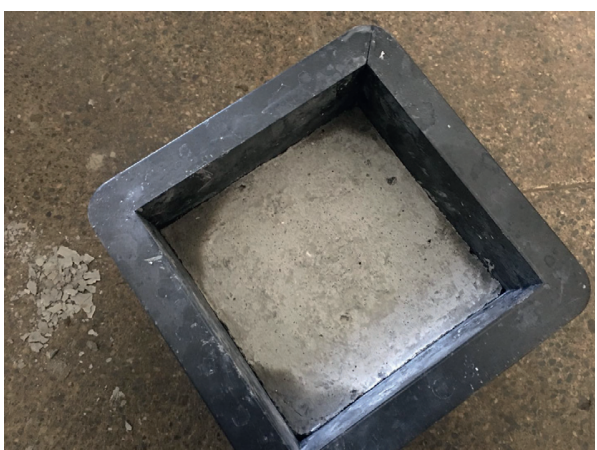

(b)

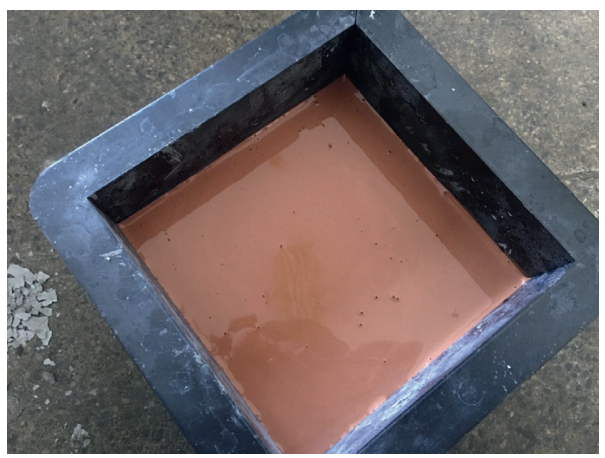

(c)

Figure 1: Procedure of making the test samples: (a) concrete cement paste; (b) after 28 days curing, the smooth contact surface with dirt removed; (c) pouring the geopolymer binder into the mould.

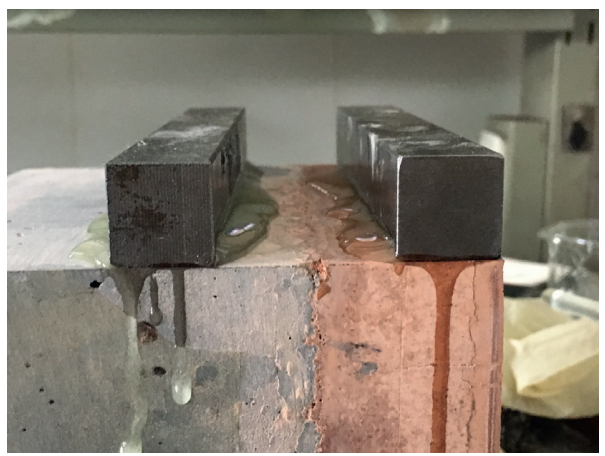

Figure 2: Smooth interface sample glued with two steel bar.
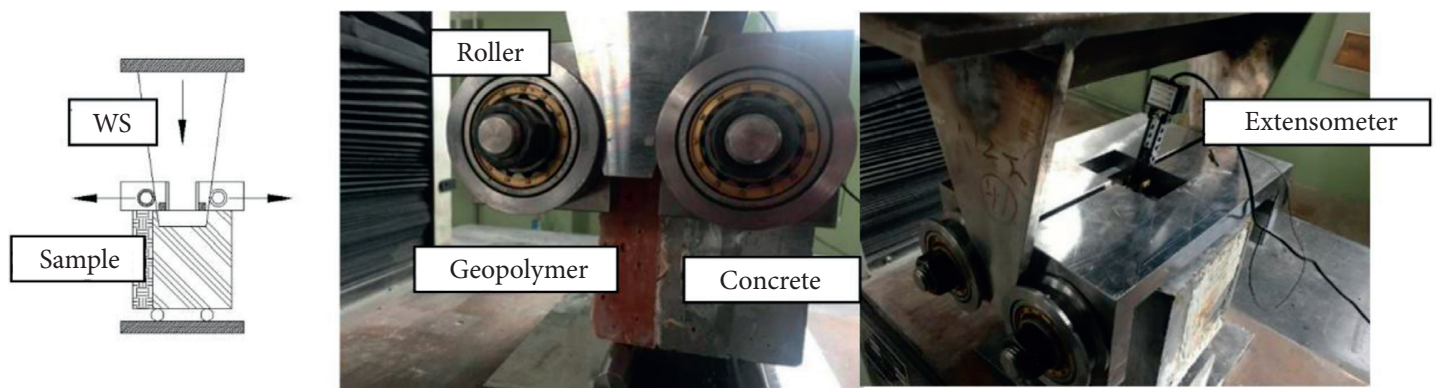

FIgUre 3: The assembled equipment for WS test.

surface before coating with the geopolymer mixture. The parallel grooving was milled with the same $3 \mathrm{~mm}$ width and different depths $(5 \mathrm{~mm}, 8 \mathrm{~mm})$, shown in Figure 4 . The failure model of the interface fracture and the adhesion ability were compared with those of the control group (smooth surface). 


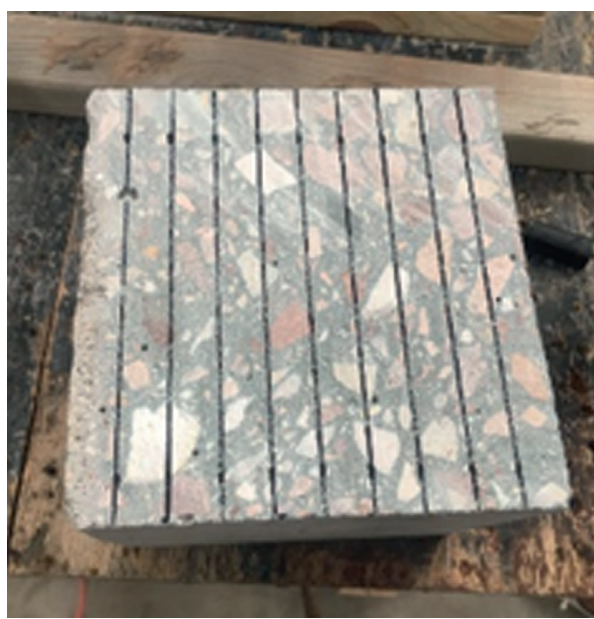

(a)

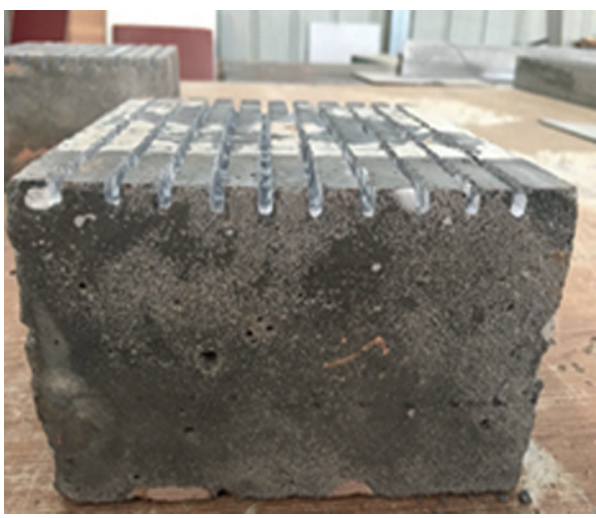

(c)

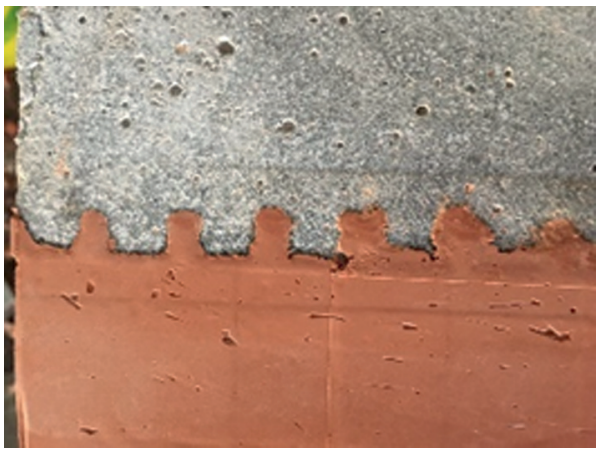

(e)

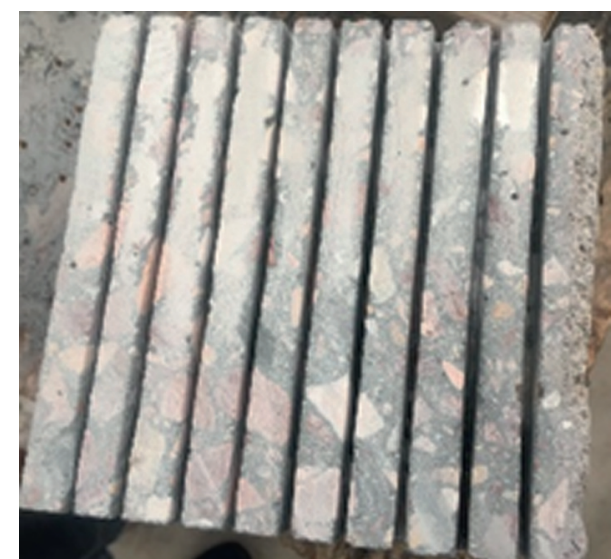

(b)

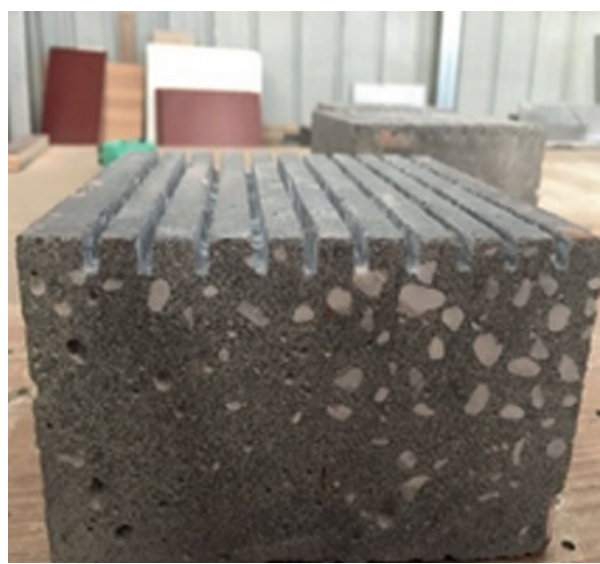

(d)

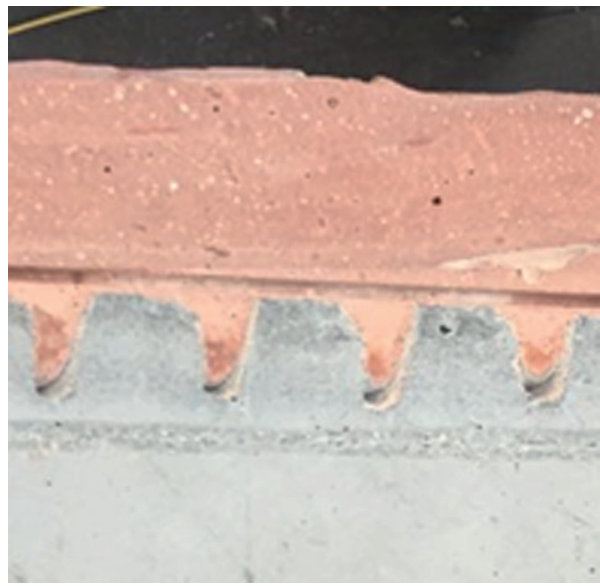

(f)

Figure 4: Different parallel groove depths and the geopolymer coating: (a) (b) (c) (d) $5 \mathrm{~mm}$ depth groove; (e) $5 \mathrm{~mm}$ depth parallel groove with geopolymer coating; (f) $8 \mathrm{~mm}$ depth parallel groove with geopolymer coating.

The orientation of the parallel grooves is also considered as an impact factor of the interfacial adhesion ability because it changes the fracture mode at the crack front mouth. To evaluate this factor, three more sets of differently orientated grooves were prepared (horizontal, diagonal, and double diagonal). To achieve the consistency of the experiment results, all specimens had the same width/depth ratio (0.375) and the same space between grooves $(10 \mathrm{~mm})$, but the orientations of the grooves were different, as shown in Figure 5. 


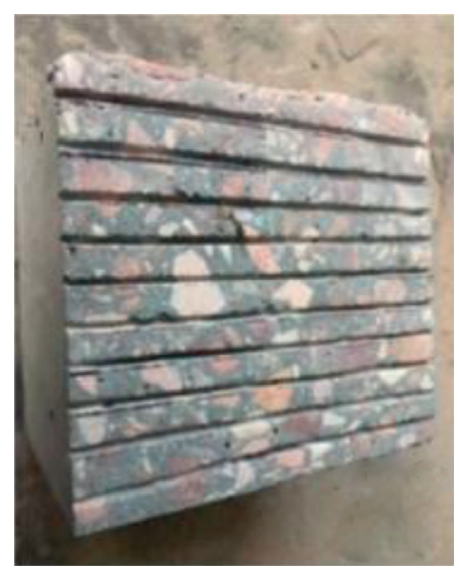

(a)

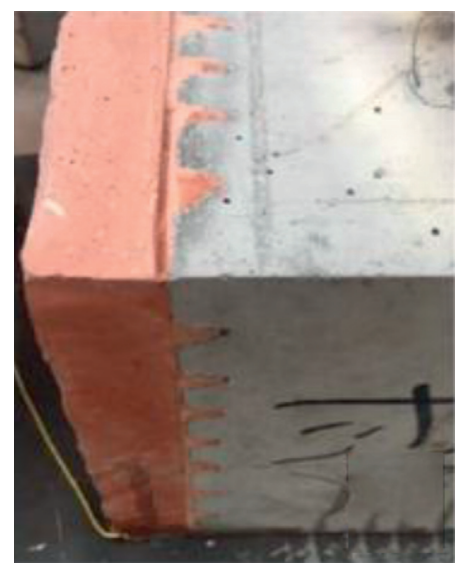

(c)

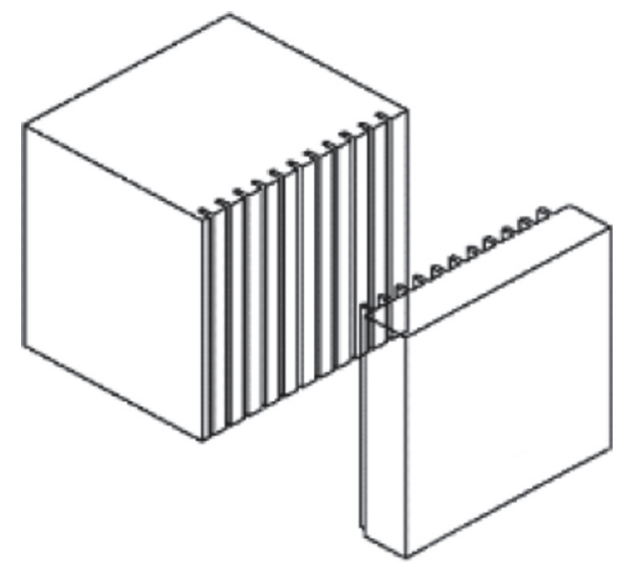

(e)

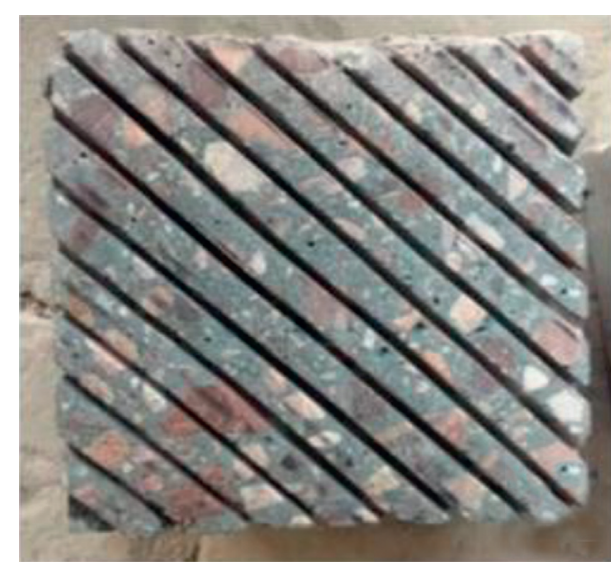

(b)

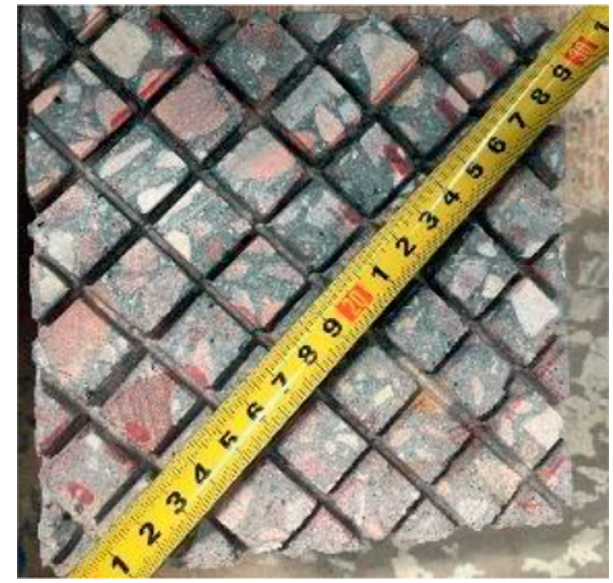

(d)

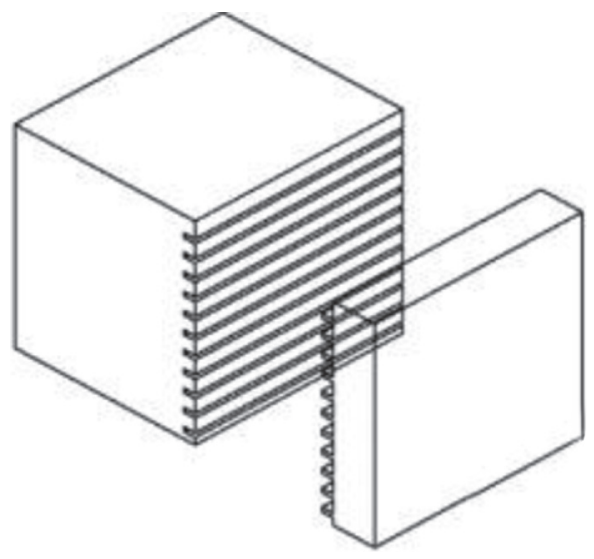

(f)

Figure 5: Continued. 


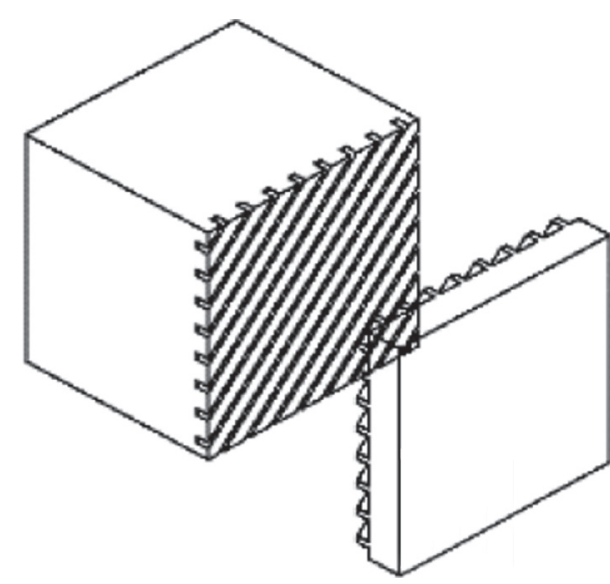

(g)

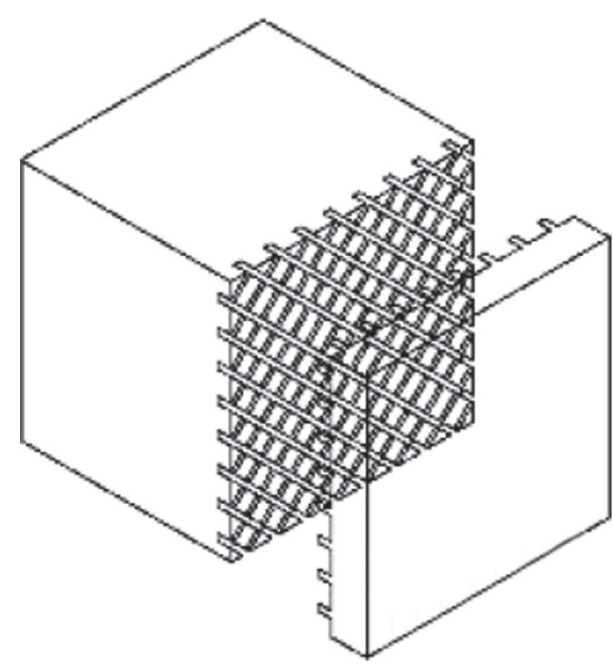

(h)

Figure 5: Geometry of the different orientations of grooving: (a) (e) vertical parallel grooves; (b) (f) horizontal parallel grooves; (c) (g) diagonal parallel grooves; (d) (h) double diagonal parallel grooves.

\section{WS Test Results}

3.1. Smooth Contact Interface. Three unmodified testing samples were prepared to acquire the $\mathrm{P}_{\mathrm{v}}$-CMOD curve for the control group as shown in Figure 6.

From the loading diagram, the fracture propagation process can be divided into three stages: crack initiation, stable expansion, and unstable propagation. For the first stage, the curve was in linear form, and the crack initial point was determined to be the point when the nonlinear decrease change in the load was firstly initiated. The load $\mathrm{P}_{\mathrm{v}}$ is equivalent to the external loading plus the self-weight of the load-transmitting plates. The values of $\mathrm{P}_{\text {vinital }}$ for sample 1 and sample 2 were nearly half of the $\mathrm{P}_{\mathrm{vmax}}$. CMOD in the first section for all three samples were only $0.04-0.13 \mathrm{~mm}$, which can be ignored. At the second stable expansion stage, the external load $\mathrm{P}_{\mathrm{v}}$ for all three samples jumped from origin to $\mathrm{P}_{\text {vinitial }}$ and continued to reach $\mathrm{P}_{\text {vmax }}$ followed by the unstable propagation stage. The curves of sample 1 and sample 3 showed the obvious nonlinear CMOD and slow crack growth. When the CMOD overpassed the critical value, the growth of the crack length was in a stable speed until the final failure occurred. At the third unstable propagation stage, a monotonic decrease was shown in all three samples until the complete failure finally occurred. The energy that was required for the crack initiation $\left(G_{\text {initial }}\right)$ and crack extension $\left(G_{\text {average }}\right)$ can be calculated by integrating the area under the $\mathrm{P}_{\mathrm{h}}$-CMOD curve. However, the direct result from the experiment is the $\mathrm{P}_{\mathrm{v}}-\mathrm{CMOD}$, and the integration of the area under the $\mathrm{P}_{\mathrm{v}}$-CMOD curve $G_{v_{o}}$ can be converted to the area under $\mathrm{P}_{\mathrm{h}}$-CMOD curve $G_{h}$ by formula $G_{h}=G_{v o} /(2 \tan \theta)$. The final results were shown in Table 5.

The reason why these three test samples have diverse forms of $\mathrm{P}_{\mathrm{v}}$-CMOD curves is that the maximum external load is relatively small (only $0.035 \mathrm{kN}$ on average), so the curves can be easily disturbed by many factors such as the

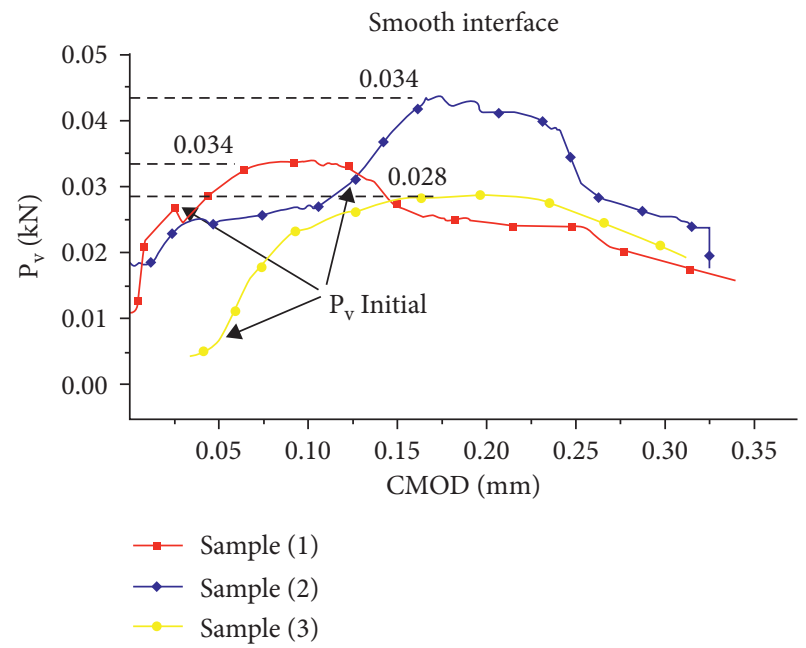

FIgURE 6: $\mathrm{P}_{\mathrm{v}}$-CMOD curve of the control group with smooth contact interface.

small preexisting fractures. Due to the increments of the compliance of the specimens, the external load will go down as well when the crack length is extended. The crack will not expand until the load exceeds $\mathrm{P}_{\text {vinitial; }}$ the height of the ligament and the crack initial point are not affected by sizes, and there is a stable expansion stage before the final fracture failure. The gradient of the initial stage indicates the resistance of the interface.

\subsection{Parallel-Grooved Interface with Different Depth/Width} Ratios. The dissymmetric geometry of the geopolymer coating (thickness of the geopolymer is $20 \mathrm{~mm}$, and the groove depth is only $5 \mathrm{~mm}$ and $8 \mathrm{~mm}$ ) was used in this study. As the width $W_{0}$ is the same for all specimens, the only difference of these specimens is the width/depth ratios of the 
TABLE 5: The WS Test results of the control samples with smooth contact interface.

\begin{tabular}{lcccccccc}
\hline Specimen & $\begin{array}{c}\mathrm{P}_{\text {vinitial }} \\
(\mathrm{kN})\end{array}$ & $\begin{array}{c}\mathrm{P}_{\text {hinitial }} \\
(\mathrm{kN})\end{array}$ & $\begin{array}{c}\mathrm{P}_{\text {vmax }} \\
(\mathrm{kN})\end{array}$ & $\begin{array}{c}\mathrm{P}_{\mathrm{hmax}} \\
(\mathrm{kN})\end{array}$ & $\begin{array}{c}\text { CMOD initial } \\
(\mathrm{mm})\end{array}$ & $\begin{array}{c}\text { Crack initial energy } \\
(\mathrm{J})\end{array}$ & $\begin{array}{c}\text { CMOD } \\
\text { final } \\
(\mathrm{mm})\end{array}$ & $\begin{array}{c}\text { Average crack energy } \\
(\mathrm{J})\end{array}$ \\
\hline Sample 1 & 0.034 & 0.063 & 0.028 & 0.052 & 0.02 & 0.0007 & 0.34 & 0.086 \\
Sample 2 & 0.06 & 0.111 & 0.034 & 0.063 & 0.005 & 0.0037 & 0.33 & 0.102 \\
Sample 3 & 0.28 & 0.522 & 0.043 & 0.080 & 0.004 & 0.0075 & 0.32 & 0.092 \\
\hline
\end{tabular}

grooves. Along with the increment of the depth of the grooves, not only the total contact area between the two materials increased, but also the dominated fracture mode at the interface transferred from mainly pure mode I to a mixed fracture mode. At the bottom edge of the grooving, the transverse stress $\sigma_{x x}$ in the interface accumulated and became the fracture driving force inside the geopolymer material.

By comparing the $5 \mathrm{~mm}$ and $8 \mathrm{~mm}$ curve gradients in Figure 7 , it was found that the increase in the initial stage of the fracture resistance was distinct. When the depth of the groove increased from $5 \mathrm{~mm}$ to $8 \mathrm{~mm}$, the damage mode transformed from a concrete-geopolymer interfacial crack to an interfacial fracture between the geopolymer and concrete surface plus the geopolymer tearing fracture. This is the main reason why the area under the $\mathrm{P}_{\mathrm{v}}$-CMOD in the $8 \mathrm{~mm}$ depth curve is much larger than that of the $5 \mathrm{~mm}$ depth curve.

As shown in Table 6, both the initial fracture toughness and the cohesive stress increased significantly with the increase of the depths of the grooves. The maximum vertical load increased from $0.022 \mathrm{kN}$ (untreated surface) to $0.3 \mathrm{kN}$ ( $8 \mathrm{~mm}$ depth of grooving), and the CMOD width increased from $0.34 \mathrm{~mm}$ to $2.02 \mathrm{~mm}$. These results indicate that the grooved interface successfully enhances the total fracture resistance.

\subsection{Parallel-Grooved Interface with Different Orientations.} The three different groups of specimens were subjected to the same WS test procedure, and the $\mathrm{P}_{\mathrm{v}}-\mathrm{CMOD}$ graphs are shown in Figure 8.

Three horizontally grooved samples were tested, but the data of only two samples have been successfully acquired due to the unique failure mode at the edge of the horizontal grooves. By observing the loading graph (Figure 8), the horizontally grooved specimen had linear behavior at the beginning, similar to the vertically grooved specimen. After the initiation of the crack, the load overpassed $0.466 \mathrm{kN}$ and quickly dropped and retained at $0.25 \mathrm{kN}$ for a longer period compared with the vertically grooved samples. As the displacement continued to be applied by the wedge, the load curve moved horizontally as the CMOD increased.

On the other hand, the diagonally parallel grooves reached the highest loading and average ERR among all the specimens. Comparing the $G_{\text {hinital }}$ of three categories of grooves, the horizontal and diagonal grooves were at the same levels. The reason for this is that most of the adhesion ability is supplied by the geopolymer strip itself at the interface and the fracture mode is different at the bottom edge of the front crack mouth along with the strip.

\section{Test Results Analysis}

To explain the WS test results, it is necessary to analyze each case in fracture mechanic perspective. When the fracture propagates along with the interface, the crack resistance capacity is dominated by two terms, the inherent fracture toughness $K_{\mathrm{IC}}^{\mathrm{ini}}$ and the cohesive fracture toughness after the initial propagation.

$$
R(\Delta l)=K_{\mathrm{IC}}^{\mathrm{ini}}\left(P_{\text {initial }}\right)+f\left(w_{s}, \Delta l, P_{\max }, M_{t}\right),
$$

where $R(\Delta l)$ is the crack extension resistance; $f\left(w_{s}, \Delta l, P_{\max }, M_{t}\right)$ is the cohesive fracture toughness. From the perspective of a fictitious fracture zone, the value of the cohesive strength $(R(\Delta l))$ is based on the cohesive stress distribution, which is a function of the CMOD width $\left(w_{s}\right)$, the maximum tensile stress, the moment near the crack tip $M_{t}$ and the crack propagation length $(\Delta l)$.

Details of external loads were reflected by the terms of SIFs $\left(K_{\mathrm{I}}, K_{\mathrm{II}}, K_{\mathrm{III}}\right)$ with additive properties. The total fracture toughness is not the intrinsic property for geopolymer, which is affected by the load mode and the shape of geometry. For brittle materials like PSS geopolymer, the fracture toughness is different in each pure mode under small-scale yielding assumption. For mode I fractures, the angular component of crack initiated just behind the crack tip will be adjusted once the crack tip was the straight line or the rough curve; but for mode II or III, as the interplane was weaker than the brittle material itself, the angular components of modes II and III were larger than those of pure mode I. This is the main reason why brittle material can bear larger external loads in modes II and III than mode I, and it is known as the "anchoring effect" in the interface mechanics.

Therefore, for any given mixed fracture mode, the nearfield solution exhibits an intrinsic spatial invariance of the combination of pure fracture mode. The superposition principle can be used for all linear elastic deformation at any point. For a given loading mode, the SIF corresponding to each load can be added together to get the final SIF term. This principle is very important for the analysis of crack systems subjected to complex loading modes.

\subsection{Fracture Mode of Parallel-Grooved Interface with Different} Width/Depth Ratios. During the experiments, the debonding damage model of the contact interface can be divided into three types (Figure 9). The first type is total delamination; the second type is mixed damage mode (i.e., the fracture delaminates along the grooves boundary); and the third type is in the plane near and parallel to the 


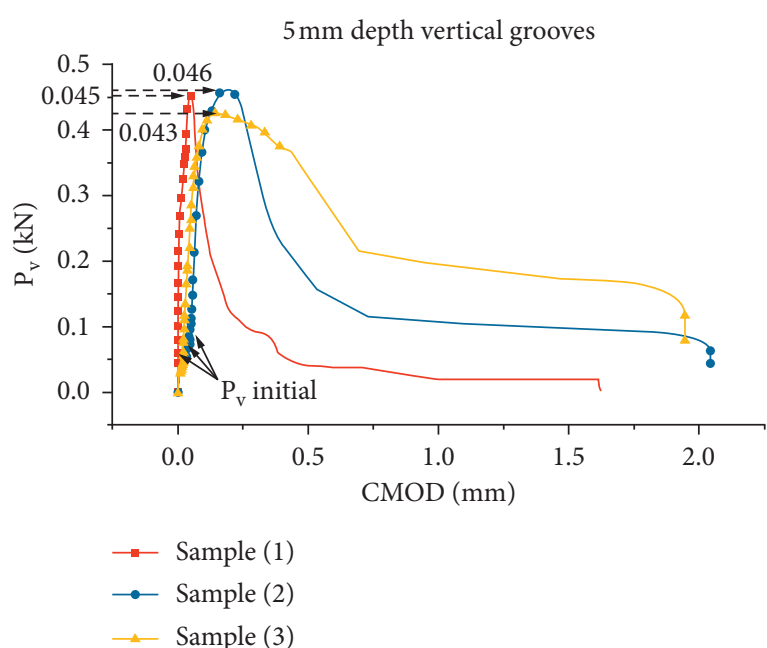

(a)

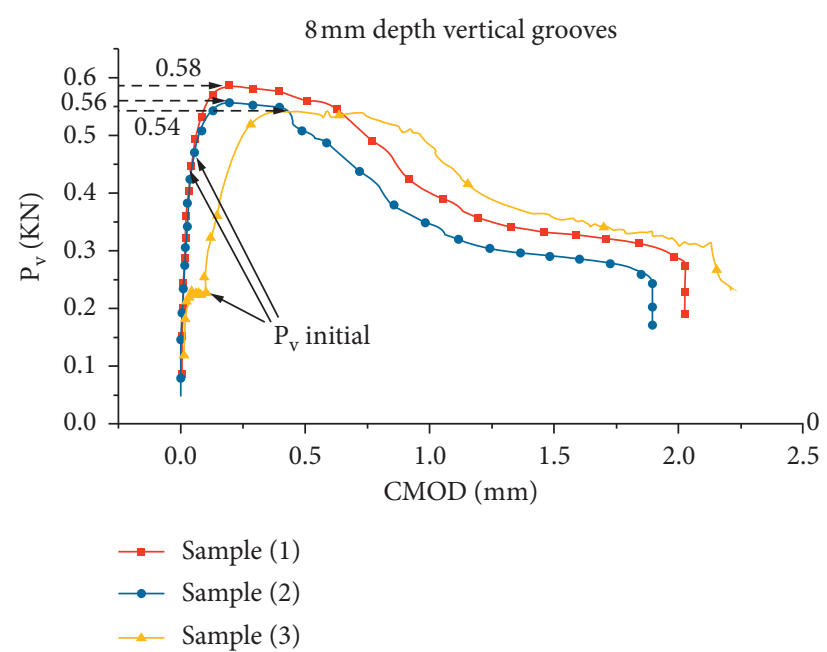

(b)

Figure 7: $\mathrm{P}_{\mathrm{v}}$-CMOD curve of different vertical parallel grooving depths.

TABLE 6: The comparison of the average ERR and CMOD of difference depths of vertical parallel grooves.

\begin{tabular}{|c|c|c|c|c|c|c|c|c|c|}
\hline Specimen & $\begin{array}{c}\mathrm{P}_{\text {vinitial }} \\
(\mathrm{kN})\end{array}$ & $\begin{array}{c}\mathrm{P}_{\text {hinitial }} \\
(\mathrm{kN})\end{array}$ & $\begin{array}{c}\mathrm{P}_{\mathrm{vmax}} \\
(\mathrm{kN})\end{array}$ & $\begin{array}{c}\mathrm{P}_{\mathrm{hmax}} \\
(\mathrm{kN})\end{array}$ & $\begin{array}{c}\text { CMOD initial } \\
(\mathrm{mm})\end{array}$ & $\begin{array}{c}\mathrm{G}_{\text {hinitial }} \\
(\mathrm{J})\end{array}$ & $\begin{array}{c}\text { CMOD Final } \\
(\mathrm{mm})\end{array}$ & $\begin{array}{c}\mathrm{G}_{\text {haverage }} \\
(\mathrm{J})\end{array}$ & $\begin{array}{l}\mathrm{W} / \mathrm{d} \\
\text { ratio } \\
\end{array}$ \\
\hline $5 \mathrm{~mm}$ Sample 1 & 0.064 & 0.119 & 0.450 & 0.840 & 0.002 & 0.001 & 1.600 & 0.168 & 0.8 \\
\hline $5 \mathrm{~mm}$ Sample 2 & 0.086 & 0.160 & 0.460 & 0.858 & 0.005 & 0.002 & 1.600 & 0.121 & 0.8 \\
\hline $5 \mathrm{~mm}$ Sample 3 & 0.061 & 0.114 & 0.450 & 0.840 & 0.005 & 0.001 & 2.040 & 0.358 & 0.8 \\
\hline $8 \mathrm{~mm}$ Sample 1 & 0.450 & 0.840 & 0.580 & 1.082 & 0.004 & 0.014 & 2.020 & 1.610 & 0.375 \\
\hline $8 \mathrm{~mm}$ Sample 2 & 0.410 & 0.765 & 0.560 & 1.045 & 0.004 & 0.013 & 1.840 & 1.724 & 0.375 \\
\hline $8 \mathrm{~mm}$ Sample 3 & 0.210 & 0.392 & 0.540 & 1.007 & 0.01 & 0.019 & 2.450 & 1.564 & 0.375 \\
\hline
\end{tabular}

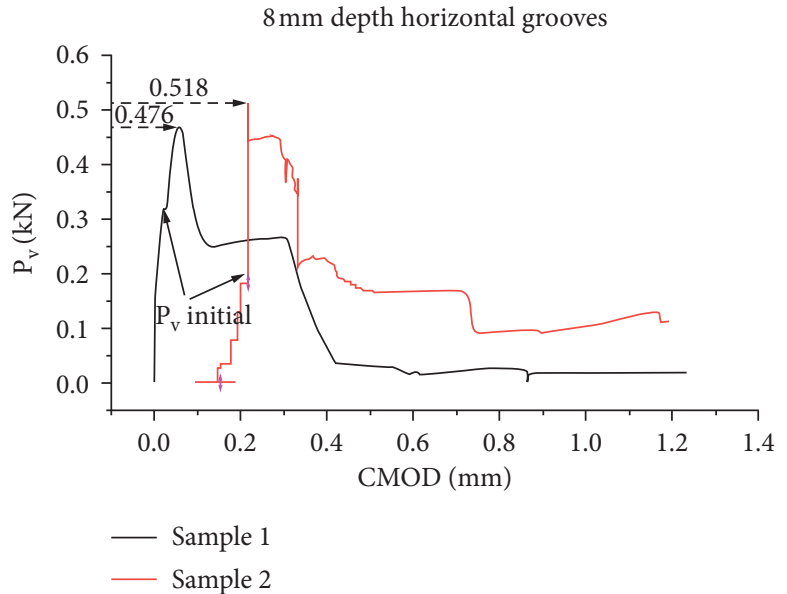

(a)

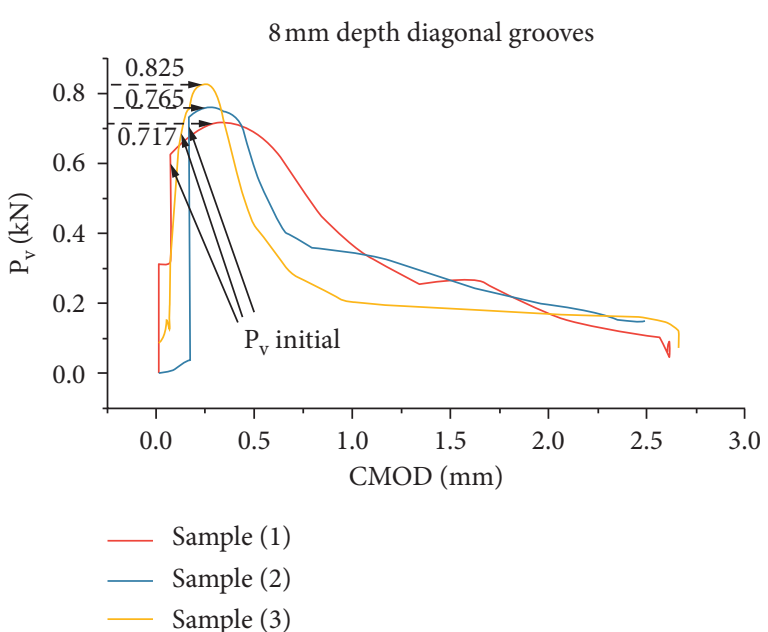

(b)

Figure 8: Continued. 


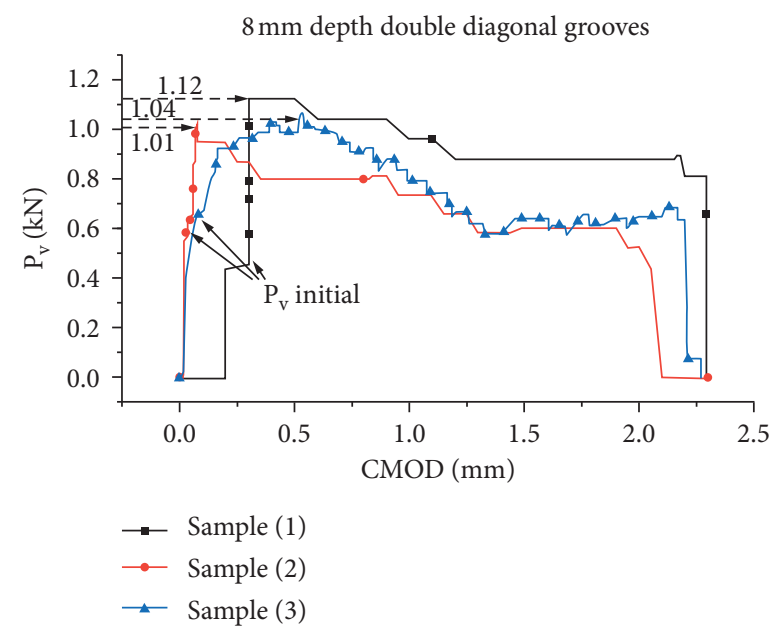

(c)

Figure 8: $\mathrm{P}_{\mathrm{v}}$-CMOD curve of different grooves orientations.

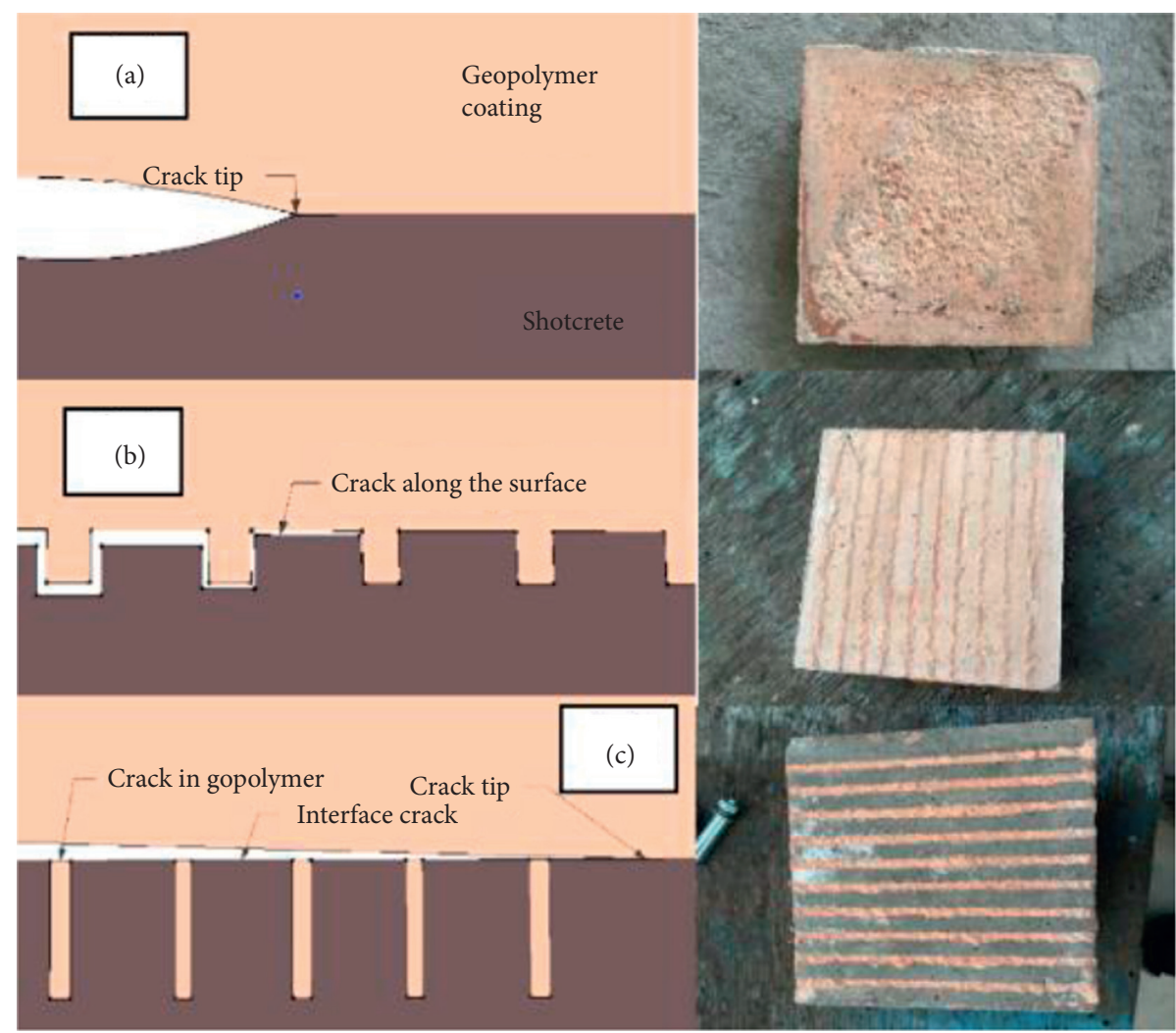

Figure 9: Change of the fracture mode along with the decrease of the width/depth ratio: (a) smooth interfacial crack; (b) high width/depth ratio; (c) low width/depth ratio.

interface. After the preresearch, we summarized the cracking conditions in Figure 9.

Unlike the bimaterial surface, the numerical value of fracture toughness can be directly calculated in single material with classical fracture mechanics theory. In this geopolymer and concrete bimaterial body, the fracture model of smooth contact interface is dominated by total delamination, and the crack is propagated in the plane near and parallel to the interface.

According to Williams [22] and Xu and Reinhardt [23], the singular stress field is universal to the cracked body. Take the stress field directly in front of the crack tip for example; the stress field can take the superposition method for the mixed fracture mode: 


$$
\begin{aligned}
\sigma_{r r}= & \frac{K_{\mathrm{I}}}{\sqrt{2 \pi r}} \cos \frac{f_{\theta i j}}{2}\left[1+\sin ^{2}\left(\frac{f_{\theta i j}}{2}\right)\right] \\
& +\frac{K_{\mathrm{II}}}{\sqrt{2 \pi r}} \sin \frac{f_{\theta i j}}{2}\left[1-3 \sin ^{2}\left(\frac{f_{\theta i j}}{2}\right)\right],
\end{aligned}
$$

where $f_{\theta i j}$ is the function with angular component. Assume the external loading condition is symmetric in the interface plane; the range of the angular component $f_{\theta i j}$ of the SIF for vertical grooves and horizontal grooves varies from $\{0,(\pi / 2)\}$. The final SIF was the combination of different local pure SIFs $\left(K_{\mathrm{I}}, K_{\mathrm{II}}, K_{\mathrm{III}}\right)$ with distinct angular and radial components.

The fracture mode is mixed by mode I (opening mode), mode II (sliding mode), and mode III (tearing mode). The sliding and tearing of the strip occurred for the diagonal direction strips. Along with the change of the fracture's orientations, the predominated fracture mode potentially shifted from mode I into mixed fracture mode. The relationship between ERR and SIFs is

$$
G=\frac{1}{\bar{E}}\left(K_{\mathrm{I}}^{2}+K_{\mathrm{II}}^{2}\right)+\frac{1}{2 \mu} K_{\mathrm{III}}^{2}
$$

This is due to the texture of geopolymer that is amorphous rather than single crystalized. According to Williams Field [13], when the fracture propagates along the dissimilar bimaterial interface, the singular field around the crack tip of the interfacial is not in square root, but at new form:

$$
\sigma_{i j}(r, \theta)=\frac{\operatorname{Re}\left[K r^{i \varepsilon}\right]}{\sqrt{2 \pi r}} f_{i j}^{\mathrm{I}}(\theta, \varepsilon)+\frac{I M\left[K r^{i \varepsilon}\right]}{\sqrt{2 \pi r}} f_{i j}^{\mathrm{II}}(\theta, \varepsilon) .
$$

The total fracture resistance $\mathrm{R}$ in the uncracked ligament is the linear elasticity range and can be achieved by combine the different pure mode SIFs $\left(K_{\mathrm{I}}, K_{\mathrm{II}}, K_{\mathrm{III}}\right)$.

4.2. Fracture Mode of Parallel-Grooved Interface with Different Orientations. When the width/depth ratio reaches the critical value, the stress concentration occurs, and the fracture propagates along the geopolymer strips' bottom side and then kinks off into one of the materials (shown in Figure 10). The point that the crack propagates into the coating layer is the region where the stress concentration at the edge of the grooves occurs. The reduction of stiffness of the geopolymer is accompanied by the crack propagate in the geopolymer coating as the displacement of the wedge continues being applied until the final failure happens. This actually has approved that horizontal orientation of the grooves is not suitable for the contact design as it fails to protect the concrete block, because once the propagation of the interfacial delamination occurs, it is quite easy for the crack to jump into the brittle geopolymer material and join with the vertical edge crack.

The fracture mode at the bottom edge of the strips is in the mixed mode due to the asymmetry of the loading patterns. Although the SIFs $\left(K_{\mathrm{I}}, K_{\mathrm{II}}, K_{\mathrm{III}}\right)$ are dependent on external boundary conditions, crack geometry, and crack length, the distribution pattern of SIFs around the crack tip is determined by the angular component function, which is independent of the loading conditions and the crack length. From this perspective, the grooves can vary not only in width/depth ratio but also in the pattern of the groove's orientations. To investigate the maximum adhesion ability influenced by the pattern of the grooves, it is necessary to conduct the investigations of the fracture modes at the bottom edge of the geopolymer strips.

\section{Mixed Fracture Mode Partition by Franc 3D}

The classical definition of fracture behavior depends on both loading conditions (preexisting crack) and properties of the fracture mode. When a specimen loses its symmetry due to the different thicknesses of upper and lower layer structures, the fracture will propagate in the mixed mode. The reason to divide the mixed mode based on the same loading condition is that the fracture is governed by different fracture criteria, and the shear force and friction resistance need to be addressed separately. Among other numerical methods to acquire the partition of the mixed mode fracture, Franc 3D uses the displacement field at the crack tip front and an extrapolation method to calculate all of the pure SIFs () at the same time.

5.1. Building Up the Geometric Model. This simulation does not consider the influence of temperature field, so only the elastic mechanical parameters of materials are set. Young's modulus of $4.1 \mathrm{GPa}$ and Poisson's ratio of 0.21 are identified for the geopolymer. The boundary condition for the bottom plane is fixed, and the displacement for the strip is $5 \mathrm{~mm}$ upwards for both models (shown in Figure 11).

After the input document is transferred from ABAQUS into Franc 3D, the initial crack is ready to be inserted into the designated location. The Franc 3D software is powerful to simulate the cracks, and it can generate multicracks, nonplanar cracks, and the cracks with arbitrary shape (Figure 12).

The shape of the crack tip is chosen as half ellipse when the short semiaxis $a=0.05 \mathrm{~mm}$ and the long semiaxis $c=0.1 \mathrm{~mm}$ (Figure 13). Step increment is set to 0.1 for both models as this simulation only focuses on the fracture mode partition at the fracture initiation stage. Since Franc 3D is a boundary element analysis system, only the surface and the crack region of the model need to be meshed, and no meshing is needed inside the model.

5.2. Computation of the Partition of SIFs. Franc 3D uses the maximum hoop criterion as the crack propagation criterion. For mode I, the program uses the crack opening displacement (COD) to calculate SIFs; for mode II, it uses the crack sliding displacement (CSD); and for mode III, it uses the crack tearing displacement (CTD). The crack front was discretized into decent amount of points, and the propagation direction of these points was determined by using two-dimensional plane strain equation. According to Franc 3D dialog reference, the expansion size depends on the 

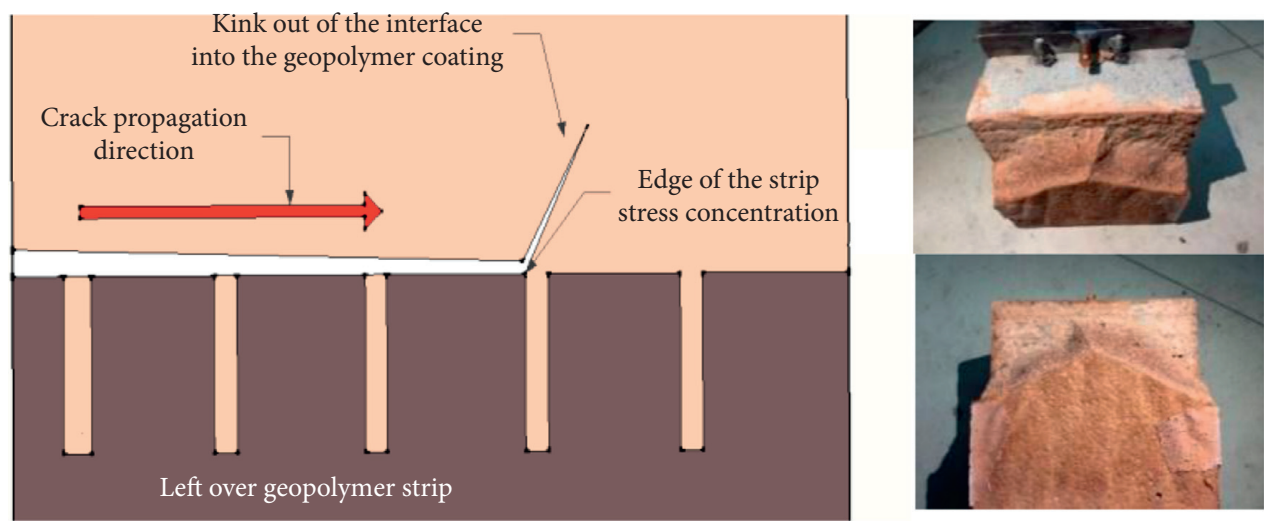

FIGURE 10: Failure mode of horizontal grooves.

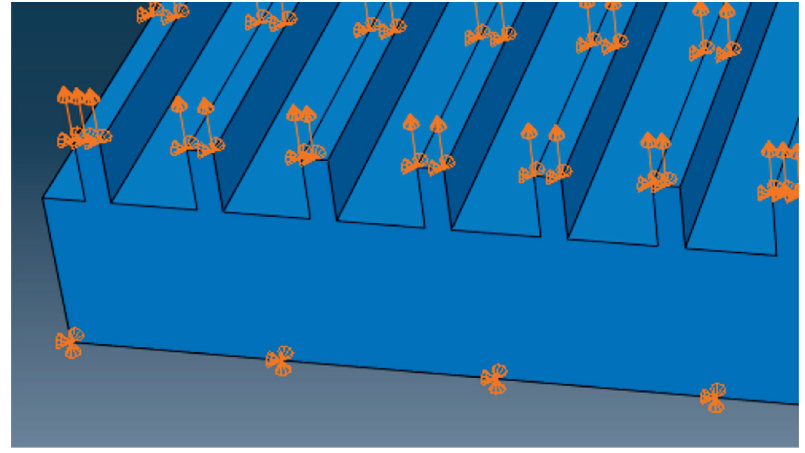

Figure 11: Boundary conditions of the vertical parallel-grooved model in ABAQUS.

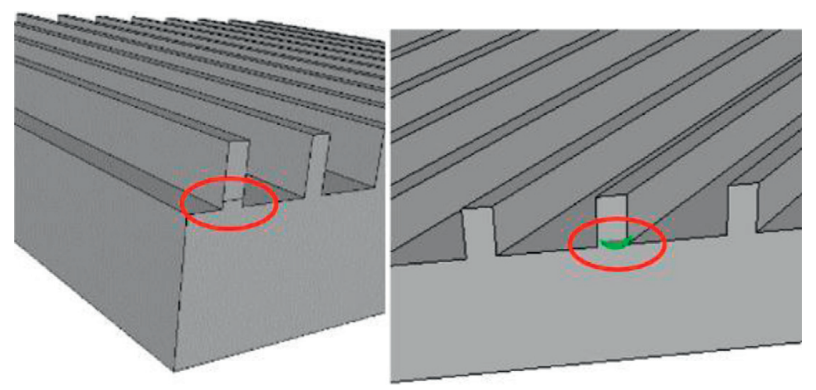

FIGURE 12: Initial cracks at the bottom edge of the geopolymer strips.

corresponding SIF of each point, and the maximum expansion size is identified by the circumstances.

$$
\begin{aligned}
& \frac{K_{\mathrm{I}}}{e \sqrt{\pi a}}=\frac{1}{E(k)}\left[\sin ^{2}\left(f_{\theta i j}\right)+\left(\frac{a}{c}\right)^{2} \cos ^{2}\left(f_{\theta i j}\right)\right]^{1 / 4}, \\
& E(k)=\int_{0}^{\pi / 2} \sqrt{1-k^{2} \sin ^{2}\left(f_{\theta i j}\right)} \mathrm{d} \theta, \quad k^{2}=\frac{c^{2}-a^{2}}{c^{2}},
\end{aligned}
$$

where $\theta$ is the angle in $f_{\theta i j}$ of the crack front, and $E(k)$ is the secondary ellipse integral. For the given $a$ and $c$, the expanded points are connected to form a new crack front mouth. Users can reanalyze the distribution of stress intensity factors at the crack front after propagation. By the
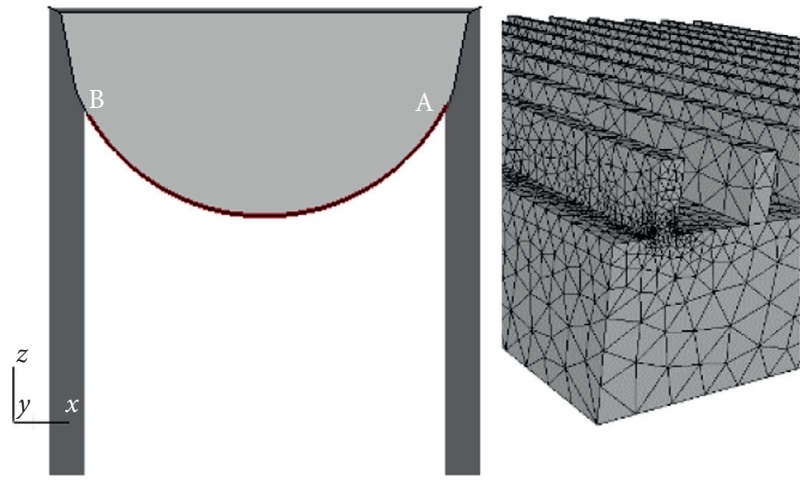

FIGURE 13: Model meshing and crack tip demonstration for both vertical and diagonal grooves.

computation of the SIFs $\left(K_{\mathrm{I}}, K_{\mathrm{II}}, K_{\mathrm{III}}\right)$, the partition of the fracture mode with the normalized distance along the crack front can be achieved.

In Figure 14, the SIF changed with the normalized distance along the crack front (from point $\mathrm{B}$ to $\mathrm{A}$, the distance is normalized from 0 to 1 ). In the vertical grooves, mode I SIF showed the parabolic curve and reached the maximum value at symmetric middle distance, while the mode II and mode III reached relatively low values at the middle distance. On the other hand, the mode I SIF in diagonal grooves monotonically decreased along the normalized crack front, and SIF for mode II and mode III increased from point A to point B. This mixed mode partition process indicates that the vertical parallel grooves are predominated by pure mode I fracture and the diagonal parallel grooves are mainly a combination of mode II and mode III fracture.

From Table 7 we can see clearly that the average energy required and the average ERR of the crack in double diagonal parallel grooves increased nearly 5 times compared with the horizontal grooves, as well as the increased capacity of the crack resistivity. The reason for this phenomenon is that the dominant fracture mode in both the vertical parallel grooves and the double diagonal parallel grooves transferred from mode I to modes II and III. Hence, these WS test results in Table 7 matched with the fracture mode partition in Figure 14. 


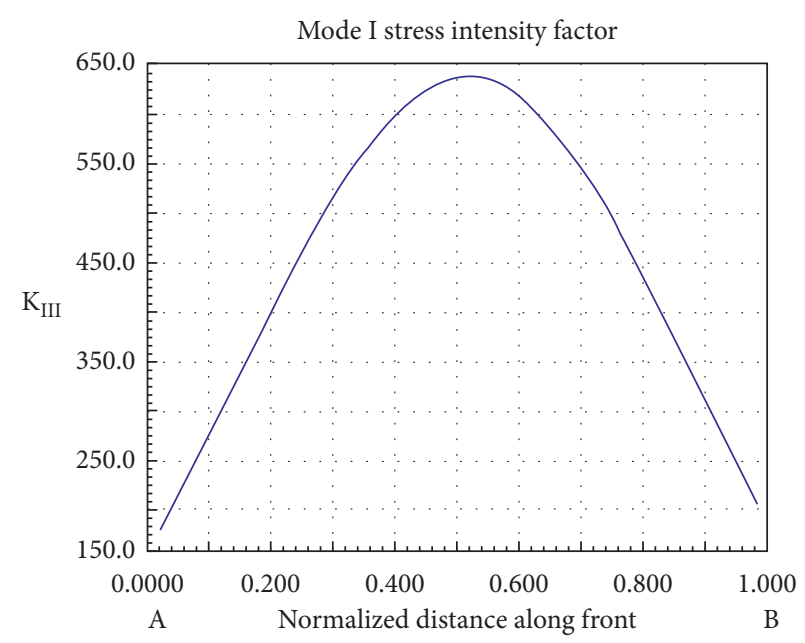

(a)

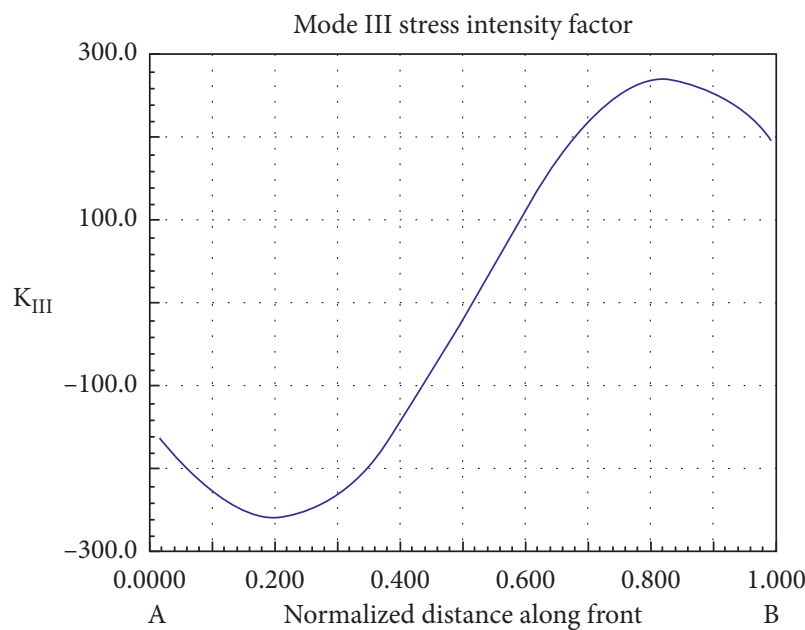

(c)

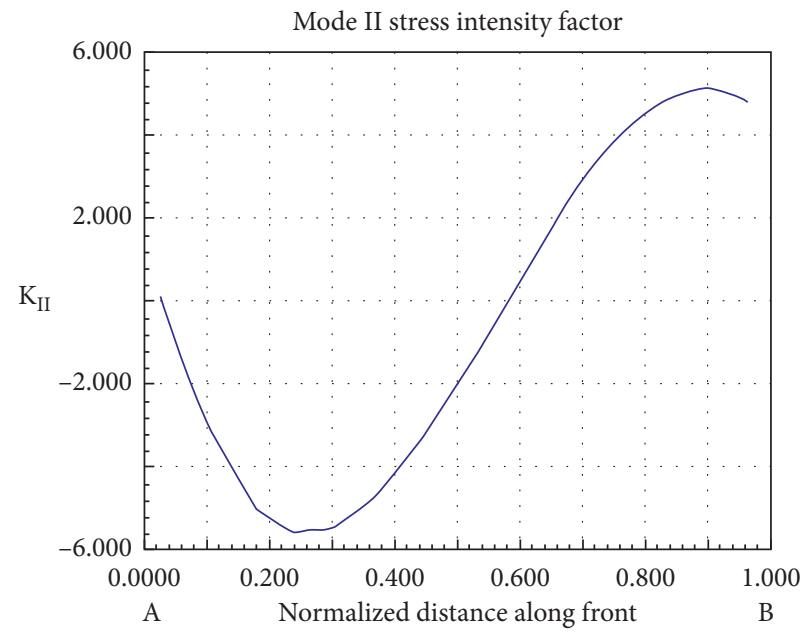

(e)

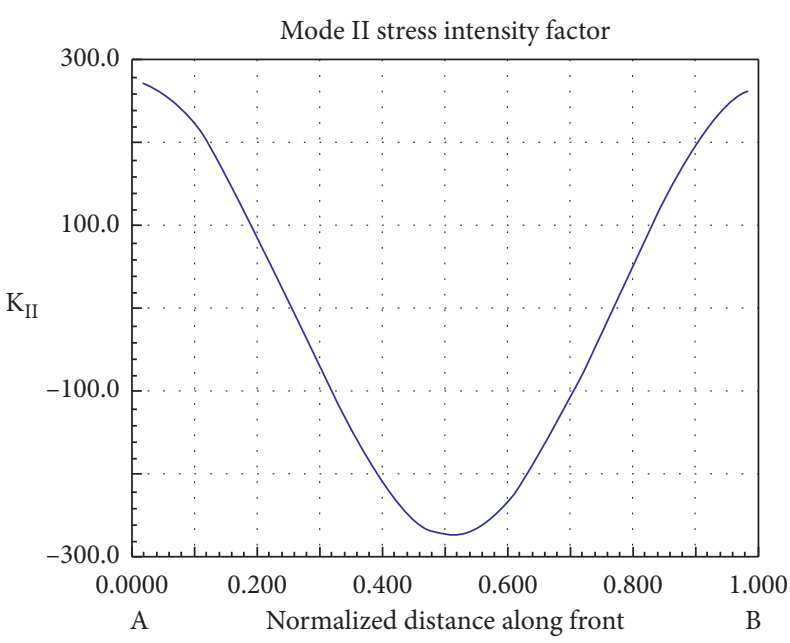

(b)

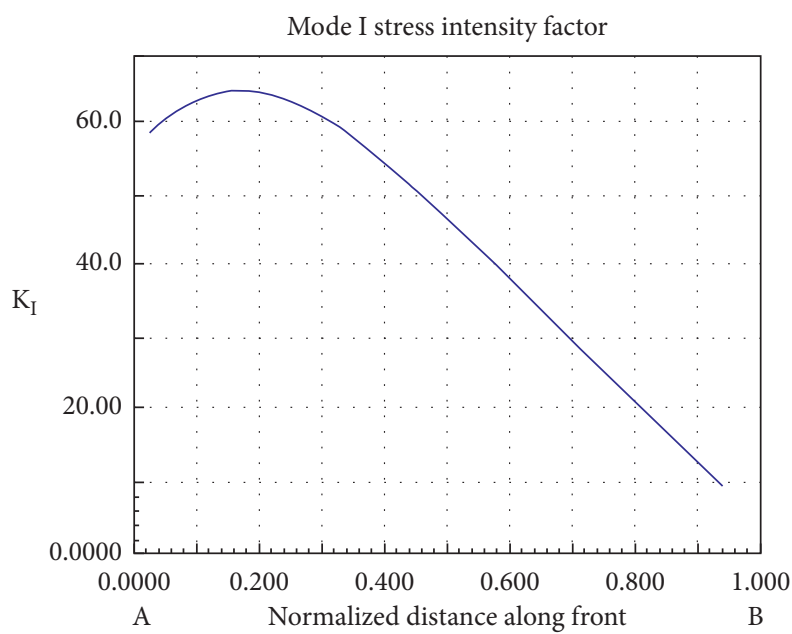

(d)

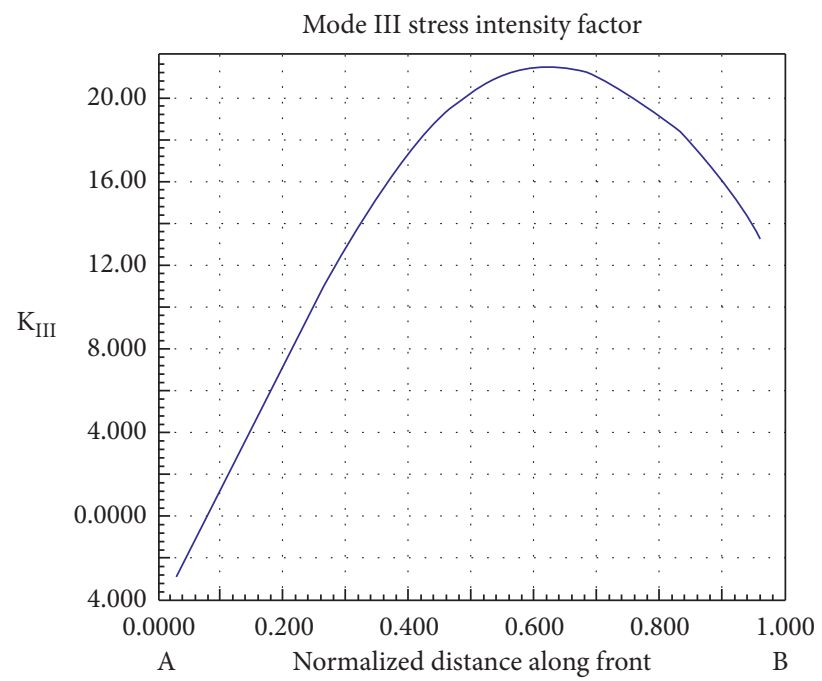

(f)

FIGURE 14: Fracture mode partition of pure SIFs for fracture at the edge of vertical parallel grooves (first three) and the fracture at the edge of diagonal parallel grooves (last three). 
TABLE 7: Comparison of the average ERR and CMOD widths of different parallel groove orientations.

\begin{tabular}{|c|c|c|c|c|c|c|c|c|c|}
\hline Specimen & $\begin{array}{c}\mathrm{P}_{\text {vinitial }} \\
(\mathrm{kN})\end{array}$ & $\begin{array}{l}P_{\text {hinitial }} \\
(\mathrm{kN})\end{array}$ & $\begin{array}{c}\mathrm{P}_{\mathrm{vmax}} \\
(\mathrm{kN})\end{array}$ & $\begin{array}{c}P_{h \max } \\
(\mathrm{kN})\end{array}$ & $\begin{array}{l}\text { CMOD initial } \\
(\mathrm{mm})\end{array}$ & $\begin{array}{l}\mathrm{G}_{\text {hinitial }} \\
(\mathrm{J})\end{array}$ & $\begin{array}{l}\text { CMOD final } \\
(\mathrm{mm})\end{array}$ & $\begin{array}{l}\mathrm{G}_{\text {haverage }} \\
(\mathrm{J})\end{array}$ & $\begin{array}{l}\mathrm{W} / \mathrm{d} \\
\text { ratio }\end{array}$ \\
\hline $\begin{array}{l}\text { Horizontal grooves sample } \\
1\end{array}$ & 0.320 & 0.597 & 0.466 & 0.869 & 0.010 & 0.015 & 1.220 & 0.228 & 0.375 \\
\hline $\begin{array}{l}\text { Horizontal grooves sample } \\
2\end{array}$ & 0.210 & 0.391 & 0.518 & 0.966 & 0.200 & 0.011 & 1.180 & 0.300 & 0.375 \\
\hline Vertical grooves sample 1 & 0.450 & 0.840 & 0.580 & 1.082 & 0.014 & 0.004 & 2.020 & 0.726 & 0.375 \\
\hline Vertical grooves sample 2 & 0.410 & 0.765 & 0.560 & 1.045 & 0.013 & 0.003 & 1.840 & 0.693 & 0.375 \\
\hline Vertical grooves sample 3 & 0.210 & 0.391 & 0.540 & 1.007 & 0.019 & 0.019 & 2.450 & 0.801 & 0.375 \\
\hline Diagonal grooves sample 1 & 0.491 & 0.916 & 0.717 & 1.338 & 0.004 & 0.034 & 2.600 & 0.931 & 0.375 \\
\hline Diagonal grooves sample 2 & 0.411 & 0.767 & 0.765 & 1.427 & 0.010 & 0.021 & 2.500 & 1.020 & 0.375 \\
\hline Diagonal grooves sample 3 & 0.521 & 0.972 & 0.825 & 1.539 & 0.022 & 0.032 & 2.700 & 1.090 & 0.375 \\
\hline $\begin{array}{l}\text { Double diagonal grooves } \\
\text { sample } 1\end{array}$ & 0.570 & 1.063 & 1.120 & 2.090 & 0.040 & 0.040 & 2.400 & 1.310 & 0.375 \\
\hline $\begin{array}{l}\text { Double diagonal grooves } \\
\text { sample } 2\end{array}$ & 0.591 & 1.103 & 1.040 & 1.940 & 0.003 & 0.030 & 2.100 & 1.423 & 0.375 \\
\hline $\begin{array}{l}\text { Double diagonal grooves } \\
\text { sample } 3\end{array}$ & 0.631 & 1.177 & 1.010 & 1.884 & 0.003 & 0.101 & 2.240 & 1.562 & 0.375 \\
\hline
\end{tabular}

\section{Conclusions}

The combination of different angular components for each pure mode has explained the increment of the external applying force successfully. The results of these tests have revealed the following highlights:

(1) The SIFs of ungrooved surface indicate that the adhesion ability of the meta-kaolin alkali-activated geopolymer is not adequate for a coating with an acceptable thickness. Total delamination failure is the main threat for this bimaterial system. The failure mode unveils that the porosity of this brittle material is relatively high. The depths of the remaining hydrated geopolymer are only $0.2-0.5 \mathrm{~mm}$ on the top of the concrete, and this is the evidence for the deficit of the interfacial resistance.

(2) The fracture energy to tear up the geopolymer itself is much greater than the fracture initialed along the bimaterial interface due to the different chemical bonds. Double diagonal parallel grooving is a method that can successfully facilitate the mechanical bonding, which increases the fracture resistance as well as the ligament area during the cracking process.

(3) These results are in agreement with previous fracture mechanics theory. However, as a promising fire protection material, geopolymer still needs to be optimized and standardized before the large-scale implementation in tunnel structure.

From this study, we successfully approved the double diagonal grooving with specific $\mathrm{W} / \mathrm{d}$ ratio as one feasible method to increase the adhesion ability between solid concrete lining structure and fire resistance geopolymer coating. These conclusions lay the ground for future studies of the constitutive failure model at the contact interface of solid concrete and geopolymer bimaterial system. These findings will provide important references to minimize the potential damage to concrete lining structures attacked by fire accidents.

\section{Data Availability}

All the data included in this study are available upon request by contact with the corresponding author.

\section{Conflicts of Interest}

The authors declare that they have no conflicts of interest.

\section{Acknowledgments}

This paper was funded by the Open project of State Key Laboratory of civil engineering disaster prevention, Tongji University, China.

\section{References}

[1] A. A. Vrakas and C. Maraveas, "Design of concrete tunnel linings for fire safety," Structural Engineering International, vol. 24, no. 3, pp. 319-329, 2014.

[2] K. Sakkas, D. Panias, P. P. Nomikos, and A. I. Sofianos, "Potassium based geopolymer for passive fire protection of concrete tunnels linings," Tunnelling and Underground Space Technology, vol. 43, no. 7, pp. 148-156, 2014.

[3] Z.-g. Yan, H.-h. Zhu, and J. W. Ju, "Behavior of reinforced concrete and steel fiber reinforced concrete shield TBM tunnel linings exposed to high temperatures," Construction and Building Materials, vol. 38, no. 2, pp. 610-618, 2013.

[4] J. Davidovits, "Geopolymers," Journal of Thermal Analysis, vol. 37, no. 8, pp. 1633-1656, 1991.

[5] B. Singh, G. Ishwarya, M. Gupta, and S. K. Bhattacharyya, "Geopolymer concrete: a review of some recent developments," Construction and Building Materials, vol. 85, pp. 78-90, 2015.

[6] T. W. Cheng and J. P. Chiu, "Fire-resistant geopolymer produced by granulated blast furnace slag," Minerals Engineering, vol. 16, no. 3, pp. 205-210, 2003.

[7] A. S. Rahman and D. W. Radford, "Evaluation of the geopolymer/nanofiber interfacial bond strength and their effects on mode-I fracture toughness of geopolymer matrix at high 
temperature," Composite Interfaces, vol. 24, no. 8, pp. 817-831, 2017.

[8] Z. H. Zhang, H. J. Zhu, C. H. Zhou, and H. Wang, "Geopolymer from kaolin in China: an overview," Applied Clay Science, vol. 119, pp. 31-41, 2016.

[9] J. Temuujin, W. Rickard, M. Lee, and A. van Riessen, "Preparation and thermal properties of fire resistant metakaolin-based geopolymer-type coatings," Journal of Noncrystalline Solids, vol. 357, no. 5, pp. 1399-1404, 2011.

[10] W. D. A. Rickard, J. Temuujin, and A. van Riessen, “Thermal analysis of geopolymer pastes synthesised from five fly ashes of variable composition," Journal of Non-crystalline Solids, vol. 358, no. 15, pp. 1830-1839, 2012.

[11] J. Davidovits, Geopolymer Chemistry and Applications, Geopolymer Institute, Saint-Quentin, France, 3rd edition, 2011.

[12] R. E. Lyon, P. N. Balaguru, A. Foden, U. Sorathia, J. Davidovits, and M. Davidovics, "Fire-resistant aluminosilicate composites," Fire and Materials, vol. 21, no. 2, pp. 67-73, 1997.

[13] S. L. Xu, X. F. Zhang, and D. Bu, "Relationship between crack tip opening displacement (CTOD) and crack mouth opening displacement (CMOD) throughtout development of concrete crack," Engineering Mechanics, vol. 28, no. 5, pp. 64-70, 2011.

[14] K. Yu and Z. Lu, "Residual crack extension resistance of postfire wedge-splitting normal strength concrete specimen based on the cohesive force function," Construction and Building Materials, vol. 54, no. 3, pp. 270-281, 2014.

[15] E. Brühwiler and F. H. Wittmann, "The wedge splitting test, a new method of performing stable fracture mechanics tests," Engineering Fracture Mechanics, vol. 35, no. 1-3, pp. 117-125, 1990.

[16] X. U. Shi-Lang, B. U. Dan, and X. F. Zhang, "Determination of fracture energy of concrete using wedge-splitting test on compact tension specimens," Journal of Hydraulic Engineering, vol. 38, no. 6, pp. 683-689, 2007.

[17] S. Xu, Y. Zhao, Z. Wu et al., "Experimental study on the fracture energy of concrete using wedge splitting specimens," Journal of Hydroelectric Engineering, vol. 38, no. 6, pp. 683-689, 2007.

[18] D. K. Shetty, A. R. Rosenfield, and W. Duckworth, "Analysis of indentation crack as a wedge-loaded half-penny crack," Journal of the American Ceramic Society, vol. 68, no. 2, pp. C65-C67, 2010.

[19] D. Mostofinejad and E. Mahmoudabadi, "Grooving as alternative method of surface preparation to postpone debonding of FRP laminates in concrete beams," Journal of Composites for Construction, vol. 14, no. 6, pp. 804-811, 2010.

[20] D. Mostofinejad and M. J. Hajrasouliha, "Effect of concrete strength and groove dimension on performance of grooving method to postpone debonding of frp sheets in strengthened concrete beams," Iranian Journal of Science \& Technology Transactions of Civil Engineering, vol. 37, no. 2, pp. 219-232, 2013.

[21] H. Sun, S. L. Liu, and X. G. Li, "Test analysis of shear performance on young-old concrete interface between bonded rebar and groove," Applied Mechanics \& Materials, vol. 438439, no. 6, pp. 235-239, 2012.

[22] M. L. Williams, "On the stress distribution at the base of a stationary crack," ASME Journal of Applied Mechanics, vol. 24, pp. 109-115, 1957.

[23] S. Xu and H. W. Reinhardt, "Determination of double-K criterion for crack propagation in quasi-brittle materials, part I: experimental investigation of crack propagation," International Journal of Fracture, vol. 98, no. 2, pp. 111-149, 1999. 